\title{
Neurocognitive Performance of African Americans and Hispanic Adults in Relation to Diet and Physical Activity: A Literature Review
}

\author{
Valeriy Zvonareva, b, e, Sahil Mamtani ${ }^{a}$, Sunita Yadav ${ }^{\mathrm{a}}$, Khadija Sharazi ${ }^{\mathrm{a}}$, Hussain Syed ${ }^{\mathrm{a}}$, \\ Abhishek Giria, Aaron Rodas ${ }^{\mathrm{a}}$, Polina Tregubenko ${ }^{\mathrm{a}}$, Donald Kotler ${ }^{\mathrm{a}, \mathrm{c}, \mathrm{d}}$
}

\begin{abstract}
As minorities, African Americans (AAs) and Hispanic adults face enormous discrepancies across many dimensions, including race/ ethnicity, socioeconomic status, legal status, gender, insurance status, or severity of conditions. There is a lot of evidence in the literature about the relationship between lifestyle and cognitive functioning in older adults. However, due to the infancy of research in this area, the relationship between diet, physical activity and cognitive decline in ethnic minorities remains unclear. We discussed the neurocognitive changes associated with physical activity and/or dietary aspects in Hispanic and AA adults, and explored various factors that affect physical activity and dietary changes in this population. Our analysis confirmed the convincing link between certain dietary patterns, physical inactivity and poor cognitive performance in AA and Hispanic adults. This report allowed us to draw necessary conclusions regarding the structure of Jacobi Frailty Initiative in the Bronx, NY, USA.
\end{abstract}

Keywords: Dementia; Aging; Diet; Physical activity; Cognition; Lifestyle intervention

\section{Introduction}

Among the millions of Americans today, racial and ethnic minorities have the highest rates of chronic diseases, suffer from reduced access to treatment, and are mistrustful of

Manuscript submitted May 7, 2020, accepted May 22, 2020

Published online May 30, 2020

a Jacobi Medical Center, Albert Einstein College of Medicine, Bronx, NY, USA ${ }^{\mathrm{b} S}$ School of Behavioral Sciences, California Southern University, Costa Mesa, CA, USA

${ }^{\mathrm{c}}$ Montefiore Hospital and Medical Center, Bronx, NY, USA

${ }^{\mathrm{d} N Y C}$ Health and Hospitals North Central Bronx, New York, NY, USA

'Corresponding Author: Valeriy Zvonarev, School of Behavioral Sciences, California Southern University, 3330 Harbor Blvd, Costa Mesa, CA 92626,

USA. Email: zvonarevval@gmail.com

doi: https://doi.org/10.14740/jnr594 medical care due to the historical inequality within the health care system. In New York City, the African American (AA) and Hispanic populations have higher rates and an earlier onset of chronic conditions as well as poorer health outcomes than other ethnic groups. The predicted global recession in 2020 will have a detrimental impact on healthcare disparities among these groups.

Higher rates of neurocognitive decline, comorbidities, and impaired mobility are found in frail and prefrail people, especially in underserved communities. The goal of the Jacobi Frailty Initiative is to develop and implement a lifestyle intervention program for low-income patients with prefrailty in the Bronx, New York, USA. Research linking physical fitness with positive outcomes in various aspects of biopsychosocial functioning has suggested that initiatives exploring pathways for decreasing the risk of neurocognitive decline in individuals with predisposing physical conditions are crucial.

The objective of this literature review is to explore the impact of physical activity and dietary interventions on cognitive function to identify the major aspects to consider when creating a structured program for AA and Hispanic adults at high risk of frailty in an urban community.

The primary research questions are as follows: 1) What are the neurocognitive changes associated with physical activity and/or dietary aspects in Hispanic and AA adults? 2) What are the factors that facilitate physical activity and dietary changes in Hispanic and AA adults? 3) What is the present state of knowledge on the ability to change behaviors in relation to diet and physical activity in Hispanic and AA adults?

This report serves as a knowledge base on the topic and will inform the development of goals and expectations of the proposed lifestyle intervention program. Culturally competent recommendations may improve health outcomes and the quality of life among underserved patients of Jacobi Medical Center and elsewhere, as well as contribute to the elimination of racial and ethnic health disparities.

\section{Methodology}

Preferred Reporting Items for Systematic Reviews and MetaAnalyses guidelines were partially followed in this literature 
Table 1. Study Selection Criteria

\begin{tabular}{|c|c|}
\hline Inclusion criteria & Description \\
\hline \multirow[t]{3}{*}{ Types of studies } & Publication date: January 1, 2000 and February 28, 2020 \\
\hline & Studies from any geographical location, USA preferred but not required \\
\hline & $\begin{array}{l}\text { 1) Studies using qualitative, quantitative, and mixed methods of analysis that seek to understand the patient experience } \\
\text { through direct contact with patients or direct observation and that describe the processes of lifestyle program } \\
\text { implementation and management; 2) Studies should include data about weight management and related comorbidities, a } \\
\text { specific description of diet planning or changes, and a description of the patients' level of physical activity. These include } \\
\text { original studies like lifestyle interventions and observational studies involving an assessment of physical activity, diet, } \\
\text { and cognitive function; and 3) Systematic reviews and meta-analyses with the highest quality evidence on a research topic }\end{array}$ \\
\hline \multirow[t]{3}{*}{ Types of participants } & Adults (> 40 years old) of African American or Hispanic origin \\
\hline & Overweight or obese (body mass index of 25.0 or higher) and diagnosed with at least one comorbidity \\
\hline & $\begin{array}{l}\text { 1) Being treated in any "usual care" setting: primary, secondary, or tertiary care (e.g. hospital, hospice, community, } \\
\text { home, or rehabilitation facility); and 2) Tested (e.g. physical measurements, blood work, and neuropsychological } \\
\text { assessment if present) }\end{array}$ \\
\hline $\begin{array}{l}\text { Types of outcome } \\
\text { measures }\end{array}$ & $\begin{array}{l}\text { 1) Weight changes and their pattern; 2) Diet profile changes and their pattern; 3) Physical activity changes; 4) HbA1c } \\
\text { or similar values; glycemic control; 5) Neuropsychological performance linked to changes described above; and } 6 \text { ) } \\
\text { Technical burdens (e.g. enacting lifestyle changes, performing exercises, modifying environments, taking medications, } \\
\text { and using assistive technologies) }\end{array}$ \\
\hline
\end{tabular}

PCP: primary care physician; HbA1C: hemoglobin A1C.

review. We extracted information from five electronic databases: Education Resources Information Center (ERIC), PsycINFO, MEDLINE, PubMed Central, and Google Scholar.

This review was conducted in six major steps.

First, the research questions and objectives were formulated.

Second, the literature search was performed. All the articles were exported to EndNote X7 to exclude copies and then moved to a Microsoft Access data collection form. The following aspects were included for consideration: article title, writer, journal, ISSN DOI, volume number, issue number, year of publication, page numbers, information on randomization, techniques, research participants, follow-up data collection, nature of interventions, and outcomes.

Third, the eligibility of the studies for inclusion was evaluated. The search for studies was extensive: multiple resources (both online and preprinted) were searched with specific language restrictions. The study selection criteria are outlined in Table 1.

The exclusion criteria were as follows: 1) Articles were restricted to adult studies, certain age groups, and studies targeting the same population groups of interest that share similar demographic and socioeconomic factors; 2) Studies on lifestyle interventions without specific information; 3) Articles that do not address interventions and their limitations; 4) Articles based on opinions and not on empirical evidence; 5) Reviews and editorials; and 6) Non-peer-reviewed literature.

The research team identified over 200 studies. After exclusions, 110 articles published since 2000 were available for full evaluation.

Fourth, the quality of the studies was assessed. To ensure the transparency of the literature review results, each article underwent the study quality assessment procedure. The study selection criteria described the minimum acceptable level of design. Selected studies were subjected to a more detailed quality assessment using general critical appraisal guides and design-based quality checklists provided by the National Institutes of Health Quality Assessment Tools (https://www. nhlbi.nih.gov/health-topics/study-quality-assessment-tools). This methodology ensured that these studies were suitable for inclusion in the review. Additional tables and questionnaires that are necessary to understand the underlying analysis are provided in the Supplementary Material 1 ( www.neurores. org).

Fifth, data were extracted from the studies. Data extraction and evaluation consisted of the tabulation of the study characteristics, quality, and effects. This was done to explore the differences between the studies and combine their results. Due to methodological differences, data from many studies reporting on lifestyle interventions in the target population were not combined, but their results were reported in a narrative format.

Finally, the data were interpreted. Our team analyzed the studies in a narrative way, comparing and summarizing previously published information to present a broad perspective on the topic in a readable format. The studies included in this report have significantly different methodological strengths and weaknesses; they were not evaluated as though they are equivalent. We described each of the included studies and summarized findings on the same topics for each article. We categorized the studies by population groups, interventions, and outcomes, and we attempted to compare the relationships found across studies. 


\section{Results}

\section{Physical activity in relation to overall and cognitive per- formance}

Any non-sedentary activity falls under the category of physical activities. It must be noted that the self-analysis of physical activity has several limitations such as the multiple definitions of physical activities, which affect social desirability bias and recall bias. Such physical activities are related to gross motor skills, categorized as fundamental movement skills (FMSs) found in middle-aged and elderly adults. As a result, studies that involve FMS-related activities were included in our analysis.

\section{Physical activity and cognitive functioning}

The prevalence of cognitive impairment is significantly higher among AAs than non-Hispanic whites [1]. Studies have suggested that cognitive functioning and physical performance are higher among men than women, non-Hispanic whites than AAs, community residents than facility residents, and people with more than 12 years of education [2].

Few studies with repeated and reliable measurements of physical activity in AA and Hispanic populations are available. Some recent articles indicated that regular physical activity is associated with a reduced risk of chronic diseases, increased healthy life expectancy, and improved cognitive functioning in older Americans. However, the effect of constant physical activity on the prevention of risk remains uncertain. In addition, only a small fraction of people meet the standardized physical activity guidelines [3].

Using data from the Exercise and Nutritional Interventions for Neurocognitive Health Enhancement (ENLIGHTEN) trial on a sample of 160 sedentary older individuals with cognitive impairment and cardiovascular disease risk factors but no dementia, Blumenthal et al observed significantly lower cardiovascular risk after the Dietary Approaches to Stopping Hypertension (DASH) diet intervention $(\mathrm{P}=0.03)$; this risk did not differ significantly between exercise and non-exercise groups $(P=0.71)$. With regard to physical activity, the exercise groups revealed greater improvement in a 6 -min walk distance test than the non-exercise groups did [4]. Similarly, Larson et al found that regular physical activity led to significant improvement across cognitive domains for older adults at risk of Alzheimer's disease (AD) involved in the Adult Changes in Thought study. Regular physical activity was determined by asking the participants about the activities they did for at least 15 min three times a week, which included various forms of aerobic exercises. The results demonstrated that the incidence of dementia was significantly lower in patients who exercised three or more times per week. Declining participation in regular physical activity was highest in AAs, individuals above 85 years old, and minorities. The risk reduction related to physical activity was greater in participants with lower performance profiles [5].

Similar studies have indicated that as the Hispanic population grows in the USA, health promotion programs should be adaptable both culturally and linguistically to improve physical activity adherence and prevent cognitive impairment in elderly Hispanics. Recent data showed that Hispanic adults reported low levels of daily physical activity. Data from various studies of non-Latino whites suggest that physical activity may decrease the risk of cognitive decline. A recent 5-year study of older Latinos revealed that individuals who maintained physical activity as they aged were less likely to experience a decline in their cognitive performance [6].

\section{Psychological and sociocultural aspects}

Self-regulation, a psychosocial aspect of physical activity, falls under the loosely defined umbrella of executive functions, which are a group of advanced cognitive processes that are necessary to regulate physical activities and inhibit the hedonic response to food. Both cognitive testing and neuroimaging studies have shown that regular physical activity enhances executive functions; these cognitive processes are also involved in the regulation of impulsive eating behavior [7].

Perceived but unconfirmed cognitive decline also affects older AAs' psychosocial well-being and mobility. Older AAs with self-reported cognitive decline noted its negative impact on their socio-occupational functioning and had a greater risk of health and mental health problems [8]. Older AAs' ability to perform various physical activities is predictive of disability onset and associated with poor cognitive performance. Data have shown that executive functioning has a stronger link to physical performance in older urban AA adults than cognitive functioning does [9]. Moreover, overall executive functioning, age, and body mass index (BMI) are directly associated with physical performance and altered self-esteem among older AA women [9].

Another study found that lifespace might be a valuable identifier of older adults in danger of cognitive decline. Limited lifespace, as a measure of physical activity through one's environment, can be considered an aspect of physical performance in older adults. Specifically, the study participants (49\% AAs) in the highest quartile of lifespace had a $53 \%$ lower chance of clinically significant cognitive impairment than those in the lowest quartile. However, the cause-and-effect relationships of this finding are unclear, and it is uncertain whether the availability of extra space would be associated with greater physical activity, improved mood, and greater cognition. In addition, under these circumstances, individuals would be more likely to meet physical activity guidelines [10].

Appropriate management of cognitive decline and psychiatric disorders like depression may improve glycemic control, medication compliance, and other measures of chronic conditions and cardiovascular risk, thereby prolonging life in AAs [11]. The beneficial effects of aerobic exercise on mood are also supported by the results of several studies on the aging population. Measurable decreases in attention, executive functioning, and poor physical performance have been observed in patients with mood disorders [12]. For example, Poelke et al examined the impact of physical and leisure activities on cognitive functioning in patients with mood disorders. Their results showed that although the reported symptoms did not change significantly, participants' engagement and participa- 
tion improved significantly in both physical and leisure activities. Furthermore, these exercises can help patients stay engaged, which also helps with behavioral remodeling and improves overall physical performance [13].

\section{Physical performance issues}

Statistically significant positive correlations were identified among physical activity, perceived health competence, duration of diabetes, and social well-being, indicating the potential of physical activity to decrease the risks associated with chronic illnesses, particularly in AA women [14]. Another study found that 6-month physical activity programs were effective in managing numerous physical and neurocognitive complaints in middle-aged and elderly patients [15].

The results of a culturally and linguistically tailored 6-month program to improve health and physical activity outcomes in inactive Hispanic women were both clinically and statistically significant, with higher moderate-to-vigorous physical activity (mean difference $=41.36$, standard error $(\mathrm{SE})$ $=7.93, \mathrm{P}<0.01$ ) noted in the intervention group when a 7-day physical activity recall was performed and confirmed with accelerometer readings $\left(r_{s}=0.44, \mathrm{P}<0.01\right)$ [16]. This study also showed the potential for low-cost activity monitors to provide objective measurements of activity in free-living conditions. Additionally, physically inactive older Hispanics who received attribution retraining in combination with supervised physical activities had better results with regard to increasing walking and maintaining exercise behavior at 12 months [17].

Lopez et al found that an individualized, multicomponent exercise training initiative improved cognitive abilities (i.e. executive functioning and various cognitive domains) in very frail patients during and after hospitalization. Their findings support the importance of maintaining appropriate levels of physical activity and cognitive functioning in older adults. Physical exercise had a positive effect on cognition (particularly visual space, memory, naming, attention, calculation, abstraction, orientation, and language function) in older patients $[18,19]$. Rejeski et al reported that participants who completed a 6-month walking exercise program showed improvements in the 6-min walk test and self-efficacy, suggesting that physical fitness may be directly related to positive improvements in psychosocial functioning [20].

Several other studies evaluated the effect of BMI and physical activity on balance, mobility, and activities of daily living. Higher BMI affects postural control in older women and is associated with a higher risk of falling [21]. Moreover, reviews conducted by the Steinberg Group have shown that patients' weight is a major factor in the impairment of balance and gait pattern, increased pressure on their feet, and decreased musculoskeletal strength [22]. Those who have been diagnosed with obesity are more likely to have had a previous fall, impaired gait, imbalance, and a tendency to withdraw from weight loss programs that include physical exercise. Osteoarthritis-related pain is associated with the weakening and instability of the knee-ankle ligamentous apparatus and puts older participants at risk of losing balance [23]. Studies have shown that overweight adults' self-selected speed of walking is usually slower than that of their normal-weight counterparts; they spend more time with their feet touching the ground [24] and have a shorter stride length and shorter swing period [25].

\section{Muscle mass and strength in relation to function}

Sarcopenia, the age-related loss of muscle mass and strength, has been linked to cognitive impairment in older patients in various ethnic groups [26]. To date, only a few studies have addressed the effects of muscle mass on cognitive functioning in AA and Hispanic adults. Yoon et al suggested that improving strength in older people could help preserve their muscle mass and improve their neurocognitive performance [27]. Reduced muscle mass in lower extremities has been associated with neurocognitive decline in multiple cognitive domains, including immediate and delayed recall [28]. Additionally, muscle strength was associated with a significantly lower risk of mild cognitive impairment (MCI) [29], and participants with stronger lower extremities and higher muscle mass had $34 \%$ reduced odds of poor cognitive performance (odds ratio $(\mathrm{OR})=0.66,95 \%$ confidence interval $(\mathrm{CI})=0.46-0.93, \mathrm{P}=0.02$ ) [30]. By contrast, grip strength, as a representative measure of muscle weakness in the upper extremities, was associated with a significant decline in global cognitive functioning [31, 32] and a higher risk of MCI and AD [29, 33].

Despite the evidence that increasing muscle mass prevents frailty, loss of function, and cognitive impairment, no studies have found a significant correlation between these factors in AA and Hispanic adults. Some evidence has suggested that the loss of muscle mass is strongly associated with frailty-related decline in physical functioning and that the decline may begin not from the age of 60 as previously thought but from as early as age 50. Moreover, the age of onset and the rate of functional decline may also be similar among other cultural groups and ethnic minorities [34].

Losing muscle mass can lead to multiple health problems, but evidence has shown that it is possible to delay and even reverse this process by incorporating resistance and balance training into lifestyle intervention programs [34]. Results have shown that muscle mass is more likely to be preserved in men and younger individuals with higher baseline percentages of lean muscle. Active participation in physical activities also leads to significant improvement in physical functioning, even among older participants [27].

Most successful exercise programs involve several components of physical fitness, including aerobic exercises, strength, balance, and flexibility training; this approach has been proven more effective than aerobic activities alone $[35,36]$.

Table 2 provides additional information about the components of physical activity that are beneficial for cognitive function [37-42].

\section{Dietary changes in relation to overall and cognitive per- formance}

\section{Diet quality}

Researchers agree that primary prevention is essential to creat- 
Table 2. Components of Physical Activity That Provide Cognitive Function Benefits

\begin{tabular}{llll}
\hline Component & Description & Examples & References \\
\hline $\begin{array}{l}\text { Regular sustained } \\
\text { aerobic exercise }\end{array}$ & $\begin{array}{l}\text { Aerobic exercises are associated } \\
\text { with significant improvements in the } \\
\text { majority of cognitive domains }\end{array}$ & $\begin{array}{l}\text { Brisk walking, dancing, jogging, } \\
\text { cycling, and swimming }\end{array}$ & $\begin{array}{l}\text { Antunes et al, 2015 [37]; } \\
\text { Erickson et al, 2011 [38]; } \\
\text { Colcombe et al, 2006 [39] }\end{array}$ \\
$\begin{array}{l}\text { Regular strength, weight, } \\
\text { or resistance training }\end{array}$ & $\begin{array}{l}\text { Resistance training appears to have } \\
\text { positive effects on cognition }\end{array}$ & $\begin{array}{l}\text { Squeezing rubber balls, } \\
\text { using elastic resistance } \\
\text { bands, and lifting weights }\end{array}$ & $\begin{array}{l}\text { Landrigan et al, 2019 [40]; } \\
\text { Suijo et al, 2013 [41] }\end{array}$ \\
$\begin{array}{l}\text { Flexibility and } \\
\text { balance training }\end{array}$ & $\begin{array}{l}\text { These exercises may help patients perform } \\
\text { movements necessary for safe mobility; } \\
\text { their effect on cognition is unclear }\end{array}$ & $\begin{array}{l}\text { Bending and stretching, tai } \\
\text { chi, yoga, and pilates }\end{array}$ & Teri et al, 2008 [42] \\
\hline
\end{tabular}

ing healthy eating behaviors that delay, prevent, or improve cognitive function. Of great importance are the beliefs and behaviors of individuals when it comes to eating a "healthy diet". Some researchers have suggested that aspects of a diet can worsen cognitive function, while others have reviewed the positive effects of lifestyle interventions on executive function, which in turn help prevent people from indulging in bad eating behaviors. A higher-quality diet was associated with better cognitive performance 5 years and even 25 years later in healthy middle-aged adults without a past medical history [43]. In another study, obese older men showed significant decreases in cognitive functioning when completing standardized neuropsychological tests assessing learning and visual memory [44]. A healthier diet was also associated with better performance on tests of several cognitive domains among those below the poverty line [45].

\section{The sociocultural context of eating and food selection}

Friedman et al compared the perceptions of primary care providers and their patients regarding communication practices and beliefs about lifestyle and healthy eating behaviors that benefit individuals' overall well-being and maintenance of good cognitive performance. Although providers were constantly involved in patient education, participants reported receiving this information from other sources $[45,46]$.

Consistent with previous research, a study conducted in New York City reported that affordability, access to healthy food, health knowledge, and personal factors are important in determining healthy behaviors in AAs [47]. Participants often mentioned resilience, reliance on spirituality, dance, music, and social support as important health-enhancing factors endorsed in their AA community [47]. Among Hispanic adults, the absence of reliable access to a sufficient quantity of nutritious food was associated with more rapid cognitive decline [48].

Previous studies have shown that people with lower levels of education may eat larger amounts of unhealthy food than those with higher education levels, possibly because of their poor literacy. For example, in a survey of 269 Latinos on the use and comprehension of nutrition fact labels in East Los Angeles, $60 \%$ reported using the label while only $13 \%$ showed adequate comprehension of the information provided. This type of survey can adequately identify patients with limited literacy skills [49]. Data from the Coronary Artery Risk Development in Young Adults study showed that women, whites, and those who received higher education tended to have higher diet scores, although this sociodemographic discrepancy decreased over the years. The level of education did not modify the relationship between diet patterns and neurocognitive performance [43].

There is a need for simple labels and indicators that allow easy selection of healthy eating choices while taking into account grocery shopping time limitations and the understanding of food portion sizes. Front-of-pack labels with an institutional endorsement are better understood and support better consumer choices of products that are low in salt, low in fat, or high in fiber in an easy and simple way [50].

\section{Dietary intake and cognitive function}

Certain foods are known to support brain health and cognitive functioning. Following these dietary patterns regularly can improve the metabolism of the central nervous system, which could translate into better cognitive and executive functioning. An excessive intake of total sugars, added sugars, and sugar-sweetened beverages was significantly associated with lower neurocognitive performance after adjusting for several covariates [51]. Conversely, a higher quantity and quality of fruit and vegetable consumption was associated with better neuropsychological performance, executive function, and several individual assessments [52]. A higher intake of fruits and vegetables rich in antioxidants such as vitamin E may alleviate the harmful effects of oxidative stress on cognitive function. For example, results of the National Health and Nutrition Examination Survey $(n=2,702)$ showed that Mexican-American patients who had five or more servings of fruits and vegetables per day had significantly decreased odds of cognitive decline and $84 \%$ decreased odds of being at risk of dementia compared with those who did not follow these guidelines [53].

A cross-sectional study conducted by Nutaitis et al showed that AAs were more likely to develop diminished functional performance when they were exposed to a diet rich in pies, mashed potatoes, sugary drinks, and oil-rich foods or to southern diets in general. Although Caucasians were equally affected, AAs showed a greater decline, and other factors such as 
Table 3. Summary of Dietary Factors and Their Effect on Cognitive Function

\begin{tabular}{|c|c|c|}
\hline Dietary factor & Description & References \\
\hline $\begin{array}{l}\text { Lower intake of saturated } \\
\text { and trans unsaturated fats }\end{array}$ & $\begin{array}{l}\text { Intake levels of both saturated and transfat are positively and } \\
\text { significantly associated with Alzheimer's disease risk }\end{array}$ & $\begin{array}{l}\text { Morris et al, } 2003[61] \\
\text { Laitinen et al, } 2006 \text { [62] }\end{array}$ \\
\hline $\begin{array}{l}\text { Higher consumption of } \\
\text { omega- } 3 \text { fatty acids }\end{array}$ & $\begin{array}{l}\text { Regular intake of omega- } 3 \text { fatty acids may provide some benefits } \\
\text { for patients with dementia, but these effects are limited }\end{array}$ & $\begin{array}{l}\text { Burckhardt et al, } 2016 \\
\text { [65]; Lim et al, } 2006 \text { [66] }\end{array}$ \\
\hline $\begin{array}{l}\text { Intake of some antioxidants } \\
\text { and vitamins }\end{array}$ & $\begin{array}{l}\text { Vitamin and/or antioxidant consumption has } \\
\text { no clear effect on cognitive decline }\end{array}$ & $\begin{array}{l}\text { Luchsinger et al, } 2003 \text { [67]; } \\
\text { Polidori et al, } 2014 \text { [68] }\end{array}$ \\
\hline Limited alcohol consumption & $\begin{array}{l}\text { The risk of cognitive decline is higher in people who } \\
\text { abstained from alcohol or consumed }>14 \text { units/week }\end{array}$ & $\begin{array}{l}\text { Koch et al, } 2019[69] \\
\text { Severine et al, } 2018[70]\end{array}$ \\
\hline $\begin{array}{l}\text { Higher percentage of fruits } \\
\text { and vegetables in diet }\end{array}$ & $\begin{array}{l}\text { A diet with a higher consumption of fruits and vegetables is } \\
\text { associated with a reduced risk of cognitive impairment }\end{array}$ & Jiang et al, 2017 [71] \\
\hline
\end{tabular}

poor socioeconomic status had a significant impact on functional performance [54]. Higher circulating levels of homocysteine were associated with neurocognitive decline in some population-based studies [55].

D-galactose, a metabolic derivative of lactose, has been extensively used to induce neurodegeneration in animal models. Findings from a study of 13,751 individuals showed that milk consumption ( $>1$ glass/day) was linked to a significantly faster decline in the global z-score over a 20 -year period. While the estimated prevalence of lactase non-persistent (LNP) genotype among AAs has been reported at $80 \%$, the negative effect of milk consumption on cognitive functioning was greater among patients classified as LNP with a milk intake less than one glass a day in comparison with nonconsumers. However, this data is problematic due to the small sample size of patients labeled as LNP. Moreover, lactase persistent (LP) or LNPstratified analysis has not revealed any association with milk intake, especially in the LP population [56].

Phytoestrogens are among the most controversial topics in the realm of nutrition today. Some authors have reported that dietary supplements consisting of phytoestrogens have neuroprotective and anti-inflammatory properties. A higher intake of isoflavones and lignans was associated with better neurocognitive performance in middle-aged and older Asian women but had no significant effects in AA and Hispanic patients [57]. A low intake of omega-3 (n-3) fatty acids in the 60 - 75 age group was associated with a higher risk of cognitive decline and metabolic syndrome in Hispanics and Puerto Ricans, while dietary consumption of $n-3$ very long chain fatty acid may have a positive impact on their executive function [58].

The DASH diet is part of the current national recommendations for the prevention and treatment of hypertension. This eating plan includes vegetables, fruits and lots of whole grains, and moderate amounts of low-fat dairy products. The DASH diet is effective in reducing blood pressure in all segments of the population and particularly effective in AAs, a group that is disproportionately affected by cardiovascular disease and in whom neurocognitive decline is twice as likely to develop compared with non-Hispanic whites [4]. In one study, com- bining regular exercise with this diet and caloric restriction improved neurocognitive performance among inactive adults with elevated blood pressure and obesity [35].

Several studies have found that following a Mediterranean-style diet in later life is associated with slower cognitive decline and a reduced risk of dementia in middle-aged and older Puerto Rican and Hispanic adults [52, 59, 60]. Finally, evidence has shown that a diet rich in fruits, vegetables, and cereals and low in red meat and sugar might reduce the risk of dementia. While conducting this review, we identified the most well-known dietary factors that might decrease the risk of mental decline and dementia. It is also worth mentioning that the dietary intake, population characteristics, and cognitive function measurements varied significantly across studies, which affected our findings and further suggestions. It is also important to emphasize that the presence of a statistical association does not guarantee a change in outcome in response to a change in behavior.

Table 3 summarizes these dietary factors and provides additional information that might not be directly related to the article's primary aim but is important to consider when discussing the impact of diet on cognition [61-71].

\section{Role of other aspects in neurocognitive decline among AA and Hispanic adults}

\section{Metabolic factors}

A number of dietary and environmental factors have been associated with an increased risk of developing dementia in middle-aged and older Americans. However, their interconnection with a specific race remains questionable. Staying socially active and engaging in other recreational activities has been noted as an important factor of healthy aging within many ethnic groups, including AAs [72].

Previous research such as the Whitehall II study has shown that obesity and a sedentary lifestyle are strongly associated with an increased risk of major neurocognitive disorder, 
although the relationship in older adults is still unclear [73]. A higher BMI is a significant risk factor for dementia because it not only triggers vascular dementia but also increases the production of adipocyte-secreted proteins and inflammatory cytokines [74]. In addition, it results in the enormous disturbance of the blood-brain barrier and regulatory variations in lipid, protein, and carbohydrate metabolism. Obesity is also associated with endothelial dysfunction and causes cerebral hypoperfusion along with hyperproduction of $\beta$-amyloid, which tends to exacerbate endothelial function, further leading to pathogenic changes of $\mathrm{AD}$ [75]. Using a multivariate model considering income, history of transient ischemic attack, and cardiovascular diseases, the authors were able to establish a link between various cardiovascular risk factors and incident cognitive impairment among participants from the Reasons for Geographic and Racial Differences in Stroke (REGARDS) study, which had a national sample of 30,239 AAs and white Americans [76].

Diabetes and prediabetic states have consistently been listed as significant risk factors for cognitive impairment and dementia, especially in AAs and Hispanics $[14,77]$. Craft concluded that excessive insulin causes a drastic increase in levels of A-beta and inflammatory agents [78]. These consequences may cause a dramatic increase in the prevalence of neurocognitive decline in AA and Hispanic adults. Physical activity can reduce the risk of cognitive decline by enhancing insulin sensitivity. One study found that adults with a BMI $>35$ performed executive function tasks far worse than normal-weight subjects did [79]. Another group of researchers reported that obese older men showed a significant decrease in cognitive functioning when completing standardized neuropsychological tests assessing learning and visual memory [44].

On the other hand, some studies do not support the link between obesity and dementia. A meta-analysis carried out in the USA and China demonstrated that individuals with increased BMI in late life have a lower risk of dementia. Nevertheless, the study also found that increased midlife BMI is associated with a high risk of dementia later in life [80]. A 12-year study involving AAs above 65 years old revealed that a decrease in BMI appears to be an early marker for dementia. Thus, there is a need for precise monitoring of weight changes in older AAs [81].

\section{Role of health education}

Most researchers agree that appropriate patient education and understanding of health behavior are paramount in chronic disease management [82]. However, for elderly patients to realize the benefits of health changes, they must have a high level of engagement and some degree of health literacy, which might be affected by cultural factors or preexisting cognitive impairment.

In several longitudinal studies, a positive connection was noted between elderly participants' physical activity and dietary changes on the one hand and their brain health on the other; this, in turn, was linked to sustained independence [83, 84]. Walking was the most frequently mentioned physical activity. Participants lacked information regarding the recommended duration, frequency, and intensity of exercise. Moreover, their understanding of the subject was limited due to several socioeconomic and cultural factors [83].

Based on the results of the Chicago Health and Aging Project, which attempted to address the shortcomings of other studies on the association of education with physical and neurocognitive performance in older adults, Barnes et al concluded that postsecondary education may benefit AAs' physical health [85]. Patients with lower levels of education $(<12$ years $)$ performed significantly worse on functional health measurements (estimate $=0.134, \mathrm{P}=0.009$ ), which increased by 0.134 points with each year of education. Similar data were obtained from other samples [86].

Some authors have noted the positive effects of a healthy physical lifestyle (not specific to physical activity) on brain health in middle-aged and elderly adults. Educational interventions have also been viewed as a way to help older adults with certain comorbidities improve their well-being and cognitive functions [84].

\section{Other factors}

ApoE $\varepsilon 4$ is one of the most well-known risk factors for AD in AAs [87]. Zhao et al reported that most common lifestyle factors in AAs are associated with the activation of multiple DNA methylation (DNAm) clocks, which are biomarkers of cellular aging [88].

Many studies have demonstrated protein energy malnutrition in patients with advanced chronic lung disease [89]. Impaired lung function in AA men has been associated with cognitive decline. Two studies on AA aging found a statistically significant relationship between the average peak expiratory flow rate and cognitive performance measurements [89]. Some authors have also suggested that bronchial asthma is more prevalent among AAs and Hispanics [89, 90]. Poor asthma control was also associated with cognitive decline in older AA and Hispanic adults. Younger patients (49\% of those aged $60-64$ vs. $28 \%$ of those aged 70 and above, $\mathrm{P}=0.0005)$, black or Hispanic patients $(43 \%$ and $48 \%$, respectively, vs. $28 \%$ of white patients, $\mathrm{P}=0.004)$, and those with poor asthma control had lower scores on several cognitive measures (e.g. processing speed, executive function, attention, and memory tests). But these measurements lost their statistical significance upon adjustment for age, sex, ethnicity, and other variables [91].

Regardless of the use of medications that suppress viral loads in human immunodeficiency virus (HIV)-positive patients, the growing middle-aged AA and Hispanic populations are at high risk of cognitive impairments due to concomitant substance abuse. Moreover, significant impairment of neuropsychological performance has been demonstrated in alcohol users, while recovery of cognitive functioning has been reported in a minority of cases [92, 93]. Although AAs start drinking at an older age and have lower levels of use in the majority of age groups [94], they are more likely to make errors in a shorter period and express greater episodic, spatial, and working memory deficits in combination with slightly deteriorated executive functioning $[95,96]$. Exposure to HIV, combined with alcohol or substance use, may have a significant 
negative impact on cognition in this target population. Heinz et al showed that excessive alcohol use was directly associated with lower total memory functioning, poorer retrieval abilities, and greater HIV symptom severity due to noncompliance with antiretroviral therapy (ART) [97]. However, patients in their 50 s and older were more likely to adhere to ART when drinking [98]. Additionally, post-HIV and ART-related cognitive changes may still be present and even exaggerated with the use of cocaine and amphetamines, causing general cognitive impairment across functions [99, 100]. Cocaine dependence was also associated with poorer verbal memory and visuospatial construction, indirectly affecting medication adherence [101].

Social motives such as peer pressure are often the cause of problematic drinking patterns in AA and Hispanic adults [102]. HIV, a deeply stigmatizing illness, frequently leads to greater health disparities in AA patients. Yet their ability to cope with the illness leads to positive cognitive and emotional changes following the HIV diagnosis [103].

\section{Practical implications}

Limited data exist on whether diet can affect the progress of neurocognitive changes in AA and Hispanic adults. The majority of observational studies support the impact of a healthy diet on cognition, while some interventional studies and lifestyle management programs have highlighted the lack of clinically significant changes. Several diets and nutritional patterns have demonstrated benefits for overall well-being and cognitive functioning. Studies have found that AAs and Hispanics who adhere to DASH or Mediterranean-style diets have a lower risk of developing cognitive dysfunction. Both diets include a variety of vegetables, fruits, grains, some fish, and small amounts of meat. It would be beneficial to avoid products with more than $5 \mathrm{~g}$ of saturated fat, $15 \mathrm{~g}$ of various sugars, or $600 \mathrm{mg}$ of salt per $100 \mathrm{~g}$ of food.

According to the World Health Organization guidelines, patients aged 65 and above are supposed to engage in $150 \mathrm{~min}$ of moderate-intensity aerobic exercise or $75 \mathrm{~min}$ of vigorousintensity aerobic exercise every week. Experts have noted that both moderate- and vigorous-intensity activities, complemented with muscle-strengthening activities, are effective in preventing neurocognitive decline [104]. They also suggested that middle-aged adults with normal cognitive functioning who engage in 3 - 4 sessions of moderate-to-vigorous-intensity exercise at least $30 \mathrm{~min}$ every week would have a lower risk of cognitive impairment in the next 10 - 15 years. Unfortunately, most patients will not adhere to these regimens, especially initially, and many modifications to these guidelines have been presented.

The amount of activity is more important than the type of exercise. There is no evidence that having one specific exercise regimen benefits cognitive function, especially in AA and Hispanic adults. A supervised multimodal program based on aerobic and resistance exercises of moderate or high intensity has the highest chance of being successful in this population.

The initial exercise regimen can gradually be increased as the patient's fitness improves, but at least $30 \mathrm{~min}$ of walking is required. This physical activity initiated in and incorporated into a patient's routine, especially in the early stages of lifestyle intervention, is more likely to be continued later in life.

In addition to identifying the potential benefits of specific diet or lifestyle interventions, a parallel goal is to promote adherence by the patient. Motivational interviewing may be used to predict a patient's readiness to change and to create and support the intrinsic motivation that is vital to making the necessary behavioral changes in relation to diet and exercise. Other strategies might also be useful. However, no data support the hypothesis that these theory-driven interventions are effective in this situation. Some researchers have provided a theoretical basis for creating physical activity programs, but their effectiveness is questionable [105]. The effectiveness of these strategies might be enhanced by considering personal characteristics such as age, health and personality features, cognitive abilities, and socioeconomic status [106].

When developing lifestyle intervention programs for AAs, we need to consider specific factors that are not very common among women of other ethnic origins: prioritizing family needs over their own, caretaking responsibilities, and other potential limitations [107, 108]. Middle-aged and older AA women have also reported that a lack of physically active AA role models negatively affects their self-perception and their desire to be physically active. Having a "motivator" (e.g. certified personal trainer or coach) with the same background may lead to significant changes in this subgroup [109, 110].

\section{Limitations of collected evidence}

There are many limitations to consider in this literature review. The strength of evidence provided by the studies was lower than expected due to the unclear risk of bias, lower level of critical appraisal, and lack of precision in some studies. We could not assess the risk of bias due to our inability to perform a meta-analysis, which prevented us from using funnel plots. We attempted to record all the measured outcomes to fully report them, but some results were ambiguous or published in an incomplete format, which may lead to reporting bias. Moreover, we did not identify any unpublished studies and non-English articles and did not use other sources; this may increase the risk of publication bias.

The randomized controlled trials (RCTs) used in this review have been associated with an unclear blinding of subjects involved in lifestyle intervention programs. Changes in behavior due to participation awareness may have affected how the subjects reported the outcomes of the intervention. While we realize that it might not always be possible in this type of research, exaggerated intervention effects could be reported, as they are a threat to the internal validity of the studies. In some articles, researchers were aware of the subjects' allocation, which could have led to observer bias. In addition, some prospective studies tried to achieve high rates of follow-up, but the potential for attrition bias was unclear. A lack of precision (e.g. small sample sizes and differences in study populations) and significant methodological variability within lifestyle interventions may have also affected our findings.

Despite these limitations, this narrative review was able to present results that support its primary aim. The evidence 
shows the significant role of physical activity, diet, and health behavior in preventing diminished cognition in AA and Hispanic adults. This finding requires further assessment through studies with larger sample sizes.

\section{Conclusions}

The literature review shows that AA and Hispanic patients who have lower levels of physical activity and do not adhere to a certain diet are more likely to develop neurocognitive deficits and diminished levels of executive function. These outcomes are closely correlated with the middle-aged and elderly population (40 years or older), participants with a lower socioeconomic status and lower level of education (12 years or less), and patients with chronic medical conditions. Our study is relevant to the Bronx population, where the rate of Alzheimer's deaths has risen gradually since 2008 .

This study was designed to provide a framework for addressing obstacles and incorporating effective strategies into the daily routine of this underserved population.

Using the outlined principles within this literature review, we will be able to draft guidelines for a lifestyle intervention that will help improve well-being through a culturally sensitive and patient-centered approach.

We realize the complexities of the behavior change process and how we can best support our participants when they hold erroneous, negative, and self-defeating views about their ability to change. It will be even more challenging to achieve long-term effects among participants who have been undertreated for many years. Furthermore, the implementation of the outlined ideas would require taking into account the neighborhoods in which the participants live and the environments in which they work, as these vary in terms of walkability, age friendliness, local policies, and safety concerns. Health behavior interventions incorporating knowledge of AA and Hispanic cultures would be sufficient to motivate our participants.

We also emphasize the importance of staff training in nutrition and behavior change strategies, which would maximize the impact of our efforts. While further research is needed, our initial findings suggest that the Jacobi Frailty Initiative might be both feasible and beneficial for the economically disadvantaged population of the Bronx, NY, USA.

\section{Supplementary Material}

Suppl 1. Results of Quality Assessment of Included Observational Cohort and Cross-Sectional Studies.

\section{Acknowledgments}

This article and the research behind it would not have been possible without the exceptional support of our supervisor, Dr. Donald Kotler, who has been supportive of our career goals and who worked actively to provide us with the protected academic time to pursue those goals. We are grateful to all of those with whom we have had the pleasure to work during this and other related projects.

\section{Financial Disclosure}

None to declare.

\section{Conflict of Interest}

None to declare.

\section{Authors Contributions}

DK encouraged VZ, SM, SY, KS, HS, AR and AG to investigate the relationships between cognition, diet and exercises, and supervised the findings of this work. VZ was in charge of overall direction and planning and developing the theoretical formalism. VZ wrote the manuscript with support from SM, AR, SY, KS, HS, and AG. VZ and SM were responsible for the article critically for important intellectual content; SM, SY, $\mathrm{KS}, \mathrm{HS}, \mathrm{AG}$ and AR conceived the presented idea and carried out the review of different sections outlined in this article. PT aided in interpreting the results and worked on the abstract. DK revised the article critically for important intellectual content and gave final approval of the version to be submitted.

\section{Data Availability}

The authors declare that data supporting the findings of this study are available within the article.

\section{References}

1. Chen N, Caruso C, Alonso A, Derebail VK, Kshirsagar AV, Sharrett AR, Key NS, et al. Association of sickle cell trait with measures of cognitive function and dementia in African Americans. eNeurologicalSci. 2019;16:100201.

2. Davey A, Elias MF, Siegler IC, Lele U, Martin P, Johnson MA, Hausman DB, et al. Cognitive function, physical performance, health, and disease: norms from the georgia centenarian study. Exp Aging Res. 2010;36(4):394-425.

3. Reiner M, Niermann C, Jekauc D, Woll A. Long-term health benefits of physical activity - a systematic review of longitudinal studies. BMC Public Health. 2013;13:813.

4. Blumenthal JA, Smith PJ, Welsh-Bohmer K, Babyak MA, Browndyke J, Lin PH, Doraiswamy PM, et al. Can lifestyle modification improve neurocognition? Rationale and design of the ENLIGHTEN clinical trial. Contemp Clin Trials. 2013;34(1):60-69.

5. Larson EB, Wang L, Bowen JD, McCormick WC, Teri L, Crane P, Kukull W. Exercise is associated with reduced risk for incident dementia among persons 65 years of age and older. Ann Intern Med. 2006;144(2):73-81. 
6. Halloway S, Wilbur J, Schoeny ME, Barnes LL. The Relation Between Physical Activity and Cognitive Change in Older Latinos. Biol Res Nurs. 2017;19(5):538-548.

7. Joseph RJ, Alonso-Alonso M, Bond DS, Pascual-Leone A, Blackburn GL. The neurocognitive connection between physical activity and eating behaviour. Obes Rev. 2011;12(10):800-812.

8. Ficker LJ, Lysack CL, Hanna M, Lichtenberg PA. Perceived Cognitive Impairment among African American elders: health and functional impairments in daily life. Aging Ment Health. 2014;18(4):471-480.

9. Schneider BC, Lichtenberg PA. Executive ability and physical performance in urban Black older adults. Arch Clin Neuropsychol. 2008;23(5):593-601.

10. Crowe M, Andel R, Wadley VG, Okonkwo OC, Sawyer P, Allman RM. Life-space and cognitive decline in a community-based sample of African American and Caucasian older adults. J Gerontol A Biol Sci Med Sci. 2008;63(11):1241-1245.

11. Musselman DL, Ziemer DC, McNutt MD, Seay JS, Royster EB, Larsen B, Barham T, et al. Depression, deficits in functional capacity, and impaired glycemic control in urban African Americans with type 2 diabetes. J Psychiatr Res. 2014;52:21-27.

12. Winchester J, Dick MB, Gillen D, Reed B, Miller B, Tinklenberg J, Mungas D, et al. Walking stabilizes cognitive functioning in Alzheimer's disease (AD) across one year. Arch Gerontol Geriatr. 2013;56(1):96-103.

13. Poelke G, Ventura MI, Byers AL, Yaffe K, Sudore R, Barnes DE. Leisure activities and depressive symptoms in older adults with cognitive complaints. Int Psychogeriatr. 2016;28(1):63-69.

14. Elasy TA, Samuel-Hodge CD, DeVellis RF, Skelly AH, Ammerman AS, Keyserling TC. Development of a health status measure for older African-American women with type 2 diabetes. Diabetes Care. 2000;23(3):325-329.

15. Stillman CM, Donahue PT, Williams MF, Callas M, Lwanga C, Brown C, Wollam ME, et al. WeightLoss Outcomes from a Pilot Study of African Dance in Older African Americans. Obesity (Silver Spring). 2018;26(12):1893-1897.

16. Marcus BH, Dunsiger SI, Pekmezi DW, Larsen BA, Bock BC, Gans KM, Marquez B, et al. The Seamos Saludables study: A randomized controlled physical activity trial of Latinas. Am J Prev Med. 2013;45(5):598-605.

17. Piedra LM, Andrade FCD, Hernandez R, Trejo L, Prohaska TR, Sarkisian CA. Let's walk! Age reattribution and physical activity among older Hispanic/Latino adults: results from the inverted exclamation markCaminemos! Randomized trial. BMC Public Health. 2018;18(1):964.

18. Saez de Asteasu ML, Martinez-Velilla N, Zambom-Ferraresi F, Casas-Herrero A, Cadore EL, Galbete A, Izquierdo M. Assessing the impact of physical exercise on cognitive function in older medical patients during acute hospitalization: Secondary analysis of a randomized trial. PLoS Med. 2019;16(7):e1002852.

19. Rovner BW, Casten RJ, Leiby BE. Determinants of Activity Levels in African Americans With Mild Cognitive Impairment. Alzheimer Dis Assoc Disord. 2016;30(1):41-
46.

20. Rejeski WJ, Spring B, Domanchuk K, Tao H, Tian L, Zhao L, McDermott MM. A group-mediated, home-based physical activity intervention for patients with peripheral artery disease: effects on social and psychological function. J Transl Med. 2014;12:29.

21. Dutil M, Handrigan GA, Corbeil P, Cantin V, Simoneau M, Teasdale N, Hue O. The impact of obesity on balance control in community-dwelling older women. Age (Dordr). 2013;35(3):883-890.

22. Steinberg N, Nemet D, Pantanowitz M, Eliakim A. Gait pattern, impact to the skeleton and postural balance in overweight and obese children: A Review. Sports (Basel). 2018;6(3):75.

23. Hirata RP, Arendt-Nielsen L, Shiozawa S, Graven-Nielsen T. Experimental knee pain impairs postural stability during quiet stance but not after perturbations. Eur J Appl Physiol. 2012;112(7):2511-2521.

24. Lai PP, Leung AK, Li AN, Zhang M. Three-dimensional gait analysis of obese adults. Clin Biomech (Bristol, Avon). 2008;23(Suppl 1):S2-6.

25. Wearing SC, Hennig EM, Byrne NM, Steele JR, Hills AP. The biomechanics of restricted movement in adult obesity. Obes Rev. 2006;7(1):13-24.

26. Tolea MI, Galvin JE. Sarcopenia and impairment in cognitive and physical performance. Clin Interv Aging. 2015;10:663-671.

27. Yoon DH, Kang D, Kim HJ, Kim JS, Song HS, Song W. Effect of elastic band-based high-speed power training on cognitive function, physical performance and muscle strength in older women with mild cognitive impairment. Geriatr Gerontol Int. 2017;17(5):765-772.

28. Low S, Ng TP, Lim CL, Moh A, Ang SF, Wang J, Goh $\mathrm{KS}$, et al. Association between Lower Extremity Skeletal Muscle Mass and Impaired Cognitive Function in Type 2 Diabetes. Sci Rep. 2020;10(1):2956.

29. Boyle PA, Buchman AS, Wilson RS, Leurgans SE, Bennett DA. Association of muscle strength with the risk of Alzheimer disease and the rate of cognitive decline in community-dwelling older persons. Arch Neurol. 2009;66(11):1339-1344.

30. Frith E, Loprinzi PD. The Association between Lower Extremity Muscular Strength and Cognitive Function in a National Sample of Older Adults. J Lifestyle Med. 2018;8(2):99-104.

31. Alfaro-Acha A, Al Snih S, Raji MA, Kuo YF, Markides $\mathrm{KS}$, Ottenbacher KJ. Handgrip strength and cognitive decline in older Mexican Americans. J Gerontol A Biol Sci Med Sci. 2006;61(8):859-865.

32. Taekema DG, Gussekloo J, Maier AB, Westendorp RG, de Craen AJ. Handgrip strength as a predictor of functional, psychological and social health. A prospective population-based study among the oldest old. Age Ageing. 2010;39(3):331-337.

33. Buchman AS, Wilson RS, Boyle PA, Bienias JL, Bennett DA. Grip strength and the risk of incident Alzheimer's disease. Neuroepidemiology. 2007;29(1-2):66-73.

34. Crespillo-Jurado M, Delgado-Giralt J, Reigal RE, Rosado A, Wallace-Ruiz A, Juarez-Ruiz de Mier R, Mo- 
rales-Sanchez $\mathrm{V}$, et al. Body composition and cognitive functioning in a sample of active elders. Front Psychol. 2019;10:1569.

35. Smith PJ, Blumenthal JA, Hoffman BM, Cooper H, Strauman TA, Welsh-Bohmer K, Browndyke JN, et al. Aerobic exercise and neurocognitive performance: a meta-analytic review of randomized controlled trials. Psychosom Med. 2010;72(3):239-252.

36. Kelly ME, Loughrey D, Lawlor BA, Robertson IH, Walsh $\mathrm{C}$, Brennan S. The impact of exercise on the cognitive functioning of healthy older adults: a systematic review and meta-analysis. Ageing Res Rev. 2014;16:12-31.

37. Antunes HK, De Mello MT, de Aquino Lemos V, SantosGalduroz RF, Camargo Galdieri L, Amodeo Bueno OF, Tufik S, et al. Aerobic physical exercise improved the cognitive function of elderly males but did not modify their blood homocysteine levels. Dement Geriatr Cogn Dis Extra. 2015;5(1):13-24.

38. Erickson KI, Voss MW, Prakash RS, Basak C, Szabo A, Chaddock L, Kim JS, et al. Exercise training increases size of hippocampus and improves memory. Proc Natl Acad Sci U S A. 2011;108(7):3017-3022.

39. Colcombe SJ, Erickson KI, Scalf PE, Kim JS, Prakash R, McAuley E, Elavsky S, et al. Aerobic exercise training increases brain volume in aging humans. J Gerontol A Biol Sci Med Sci. 2006;61(11):1166-1170.

40. Landrigan JF, Bell T, Crowe M, Clay OJ, Mirman D. Lifting cognition: a meta-analysis of effects of resistance exercise on cognition. Psychol Res. 2019.

41. Suijo K, Inoue S, Ohya Y, Odagiri Y, Takamiya T, Ishibashi $\mathrm{H}$, Itoh $\mathrm{M}$, et al. Resistance exercise enhances cognitive function in mouse. Int J Sports Med. 2013;34(4):368375.

42. Teri L, Logsdon RG, McCurry SM. Exercise interventions for dementia and cognitive impairment: the Seattle Protocols. J Nutr Health Aging. 2008;12(6):391-394.

43. Zhu N, Jacobs DR, Meyer KA, He K, Launer L, Reis JP, Yaffe $\mathrm{K}$, et al. Cognitive function in a middle aged cohort is related to higher quality dietary pattern 5 and 25 years earlier: the CARDIA study. J Nutr Health Aging. 2015;19(1):33-38.

44. Elias MF, Elias PK, Sullivan LM, Wolf PA, D'Agostino $\mathrm{RB}$. Lower cognitive function in the presence of obesity and hypertension: the Framingham heart study. Int J Obes Relat Metab Disord. 2003;27(2):260-268.

45. Wright RS, Waldstein SR, Kuczmarski MF, Pohlig RT, Gerassimakis CS, Gaynor B, Evans MK, et al. Diet quality and cognitive function in an urban sample: findings from the Healthy Aging in Neighborhoods of Diversity across the Life Span (HANDLS) study. Public Health Nutr. 2017;20(1):92-101.

46. Friedman DB, Rose ID, Anderson LA, Hunter R, Bryant LL, Wu B, Deokar AJ, et al. Beliefs and communication practices regarding cognitive functioning among consumers and primary care providers in the United States, 2009. Prev Chronic Dis. 2013;10:E58; quiz 58-13.

47. Swierad EM, Vartanian LR, King M. The Influence of Ethnic and Mainstream Cultures on African Americans' Health Behaviors: A Qualitative Study. Behav Sci (Ba- sel). 2017;7(3):49.

48. Wong JC, Scott T, Wilde P, Li YG, Tucker KL, Gao X. Food insecurity is associated with subsequent cognitive decline in the Boston Puerto Rican health study. J Nutr. 2016;146(9):1740-1745.

49. Sharif MZ, Rizzo S, Prelip ML, Glik DC, Belin TR, Langellier BA, Kuo AA, et al. The association between nutrition facts label utilization and comprehension among Latinos in two east Los Angeles neighborhoods. J Acad Nutr Diet. 2014;114(12):1915-1922.

50. De la Cruz-Gongora V, Torres P, Contreras-Manzano A, Jauregui de la Mota A, Mundo-Rosas V, Villalpando S, Rodriguez-Oliveros G. Understanding and acceptability by Hispanic consumers of four front-of-pack food labels. Int J Behav Nutr Phys Act. 2017;14(1):28.

51. Ye X, Gao X, Scott T, Tucker KL. Habitual sugar intake and cognitive function among middle-aged and older Puerto Ricans without diabetes. Br J Nutr. 2011;106(9):14231432.

52. Ye X, Scott T, Gao X, Maras JE, Bakun PJ, Tucker KL. Mediterranean diet, healthy eating index 2005, and cognitive function in middle-aged and older Puerto Rican adults. J Acad Nutr Diet. 2013;113(2):276-281, e271273.

53. Wu S, Fisher-Hoch SP, Reininger BM, McCormick JB. Association between fruit and vegetable intake and symptoms of mental health conditions in Mexican Americans. Health Psychol. 2018;37(11):1059-1066.

54. Nutaitis AC, Tharwani SD, Serra MC, Goldstein FC, Zhao L, Sher SS, Verble DD, et al. Diet as a risk factor for cognitive decline in african americans and caucasians with a parental history of alzheimer's disease: a crosssectional pilot study dietary patterns. J Prev Alzheimers Dis. 2019;6(1):50-55.

55. Wright CB, Lee HS, Paik MC, Stabler SP, Allen RH, Sacco RL. Total homocysteine and cognition in a triethnic cohort: the Northern Manhattan Study. Neurology. 2004;63(2):254-260.

56. Petruski-Ivleva N, Kucharska-Newton A, Palta P, Couper D, Meyer K, Graff M, Heiss G. Milk intake at midlife and cognitive decline over 20 years. The atherosclerosis risk in communities (ARIC) Study. Nutrients. 2017;9(10):1134.

57. Greendale GA, Huang MH, Leung K, Crawford S L, Gold EB, Wight R, Karlamangla AS. Dietary phytoestrogen intakes and cognitive function during the menopause transition: results from the SWAN phytoestrogen study. Menopause (New York, NY). 2012;19(8):894.

58. Bigornia SJ, Scott TM, Harris WS, Tucker KL. Prospective associations of erythrocyte composition and dietary intake of n-3 and n-6 PUFA with measures of cognitive function. Nutrients. 2018;10(9):1253.

59. Valls-Pedret C, Sala-Vila A, Serra-Mir M, Corella D, de la Torre R, Martinez-Gonzalez MA, Martinez-Lapiscina $\mathrm{EH}$, et al. Mediterranean diet and age-related cognitive decline: a randomized clinical trial. JAMA Intern Med. 2015;175(7):1094-1103.

60. Tsivgoulis G, Judd S, Letter AJ, Alexandrov AV, Howard G, Nahab F, Unverzagt FW, et al. Adherence to a Mediterranean diet and risk of incident cognitive impairment. 
Neurology. 2013;80(18):1684-1692.

61. Morris MC, Evans DA, Bienias JL, Tangney CC, Bennett DA, Aggarwal N, Schneider J, et al. Dietary fats and the risk of incident Alzheimer disease. Arch Neurol. 2003;60(2):194-200.

62. Laitinen MH, Ngandu T, Rovio S, Helkala EL, Uusitalo U, Viitanen M, Nissinen A, et al. Fat intake at midlife and risk of dementia and Alzheimer's disease: a populationbased study. Dement Geriatr Cogn Disord. 2006;22(1):99107.

63. Ruan Y, Tang J, Guo X, Li K, Li D. Dietary Fat Intake and Risk of Alzheimer's Disease and Dementia: A Meta-Analysis of Cohort Studies. Curr Alzheimer Res. 2018;15(9):869-876.

64. Briggs MA, Petersen KS, Kris-Etherton PM. Saturated fatty acids and cardiovascular disease: replacements for saturated fat to reduce cardiovascular risk. Healthcare (Basel). 2017;5(2):29.

65. Burckhardt M, Herke M, Wustmann T, Watzke S, Langer G, Fink A. Omega-3 fatty acids for the treatment of dementia. Cochrane Database Syst Rev. 2016;4:CD009002.

66. Lim WS, Gammack JK, Van Niekerk J, Dangour AD. Omega 3 fatty acid for the prevention of dementia. Cochrane Database Syst Rev. 2006;1:CD005379.

67. Luchsinger JA, Tang MX, Shea S, Mayeux R. Antioxidant vitamin intake and risk of Alzheimer disease. Arch Neurol. 2003;60(2):203-208.

68. Polidori MC, Schulz RJ. Nutritional contributions to dementia prevention: main issues on antioxidant micronutrients. Genes Nutr. 2014;9(2):382.

69. Koch M, Fitzpatrick AL, Rapp SR, Nahin RL, Williamson JD, Lopez OL, DeKosky ST, et al. Alcohol consumption and risk of dementia and cognitive decline among older adults with or without mild cognitive impairment. JAMA Netw Open. 2019;2(9):e1910319.

70. Sabia S, Fayosse A, Dumurgier J, Dugravot A, Akbaraly T, Britton A, Kivimaki M, et al. Alcohol consumption and risk of dementia: 23 year follow-up of Whitehall II cohort study. BMJ. 2018;362:k2927.

71. Jiang X, Huang J, Song D, Deng R, Wei J, Zhang Z. Increased consumption of fruit and vegetables is related to a reduced risk of cognitive impairment and dementia: meta-analysis. Front Aging Neurosci. 2017;9:18.

72. Laditka SB, Corwin SJ, Laditka JN, Liu R, Tseng W, Wu $\mathrm{B}$, Beard RL, et al. Attitudes about aging well among a diverse group of older Americans: implications for promoting cognitive health. Gerontologist. 2009;49(Suppl 1):S30-39.

73. Singh-Manoux A, Dugravot A, Shipley M, Brunner EJ, Elbaz A, Sabia S, Kivimaki M. Obesity trajectories and risk of dementia: 28 years of follow-up in the Whitehall II Study. Alzheimers Dement. 2018;14(2):178-186.

74. Verdile G, Keane KN, Cruzat VF, Medic S, Sabale M, Rowles J, Wijesekara N, et al. Inflammation and oxidative stress: the molecular connectivity between insulin resistance, obesity, and Alzheimer's disease. Mediators Inflamm. 2015;2015:105828.

75. Toda N, Ayajiki K, Okamura T. Obesity-induced cerebral hypoperfusion derived from endothelial dysfunction: one of the risk factors for Alzheimer's disease. Curr Alzheimer Res. 2014;11(8):733-744.

76. Gillett SR, Thacker EL, Letter AJ, McClure LA, Wadley VG, Unverzagt FW, Kissela BM, et al. Correlates of incident cognitive impairment in the reasons for geographic and racial differences in stroke (REGARDS) study. Clin Neuropsychol. 2015;29(4):466-486.

77. Hsu FC, Sink KM, Hugenschmidt CE, Williamson JD, Hughes TM, Palmer ND, Xu J, et al. Cerebral Structure and Cognitive Performance in African Americans and European Americans With Type 2 Diabetes. J Gerontol A Biol Sci Med Sci. 2018;73(3):407-414.

78. Craft S. Insulin resistance syndrome and Alzheimer's disease: age- and obesity-related effects on memory, amyloid, and inflammation. Neurobiol Aging. 2005;26(Suppl 1):65-69.

79. Boeka AG, Lokken KL. Neuropsychological performance of a clinical sample of extremely obese individuals. Arch Clin Neuropsychol. 2008;23(4):467-474.

80. Loef M, Walach H. Midlife obesity and dementia: metaanalysis and adjusted forecast of dementia prevalence in the United States and China. Obesity (Silver Spring). 2013;21(1):E51-55.

81. Gao S, Nguyen JT, Hendrie HC, Unverzagt FW, Hake A, Smith-Gamble V, Hall K. Accelerated weight loss and incident dementia in an elderly African-American cohort. J Am Geriatr Soc. 2011;59(1):18-25.

82. Adams RJ. Improving health outcomes with better patient understanding and education. Risk Manag Healthc Policy. 2010;3:61-72.

83. Wilcox S, Sharkey JR, Mathews AE, Laditka JN, Laditka SB, Logsdon RG, Sahyoun N, et al. Perceptions and beliefs about the role of physical activity and nutrition on brain health in older adults. Gerontologist. 2009;49(Suppl 1):S61-71.

84. Vance DE, Gakumo CA, Childs GD, Enah C, Fazeli PL. Perceptions of brain health and cognition in older African Americans and caucasians with HIV: a focus group study. J Assoc Nurses AIDS Care. 2017;28(6):862-876.

85. Barnes LL, Wilson RS, Hebert LE, Scherr PA, Evans DA, Mendes de Leon CF. Racial differences in the association of education with physical and cognitive function in older blacks and whites. J Gerontol B Psychol Sci Soc Sci. 2011;66(3):354-363.

86. Tsang S, Sperling SA, Park MH, Helenius IM, Williams IC, Manning C. Health variables are informative in screening for mild cognitive impairment among elderly African Americans. J Appl Gerontol. 2019;38(10):14211444.

87. Rajan KB, McAninch EA, Wilson RS, Weuve J, Barnes LL, Evans DA. Race, APOEvarepsilon4, and Long-Term Cognitive Trajectories in a Biracial Population Sample. J Alzheimers Dis. 2019;72(1):45-53.

88. Zhao W, Ammous F, Ratliff S, Liu J, Yu M, Mosley TH, Kardia SLR, et al. Education and Lifestyle Factors Are Associated with DNA Methylation Clocks in Older African Americans. Int J Environ Res Public Health. 2019; 16(17):3141

89. Sims RC, Thorpe RJ, Jr., Gamaldo AA, Aiken-Mor- 
gan AT, Hill LK, Allaire JC, Whitfield KE. Cognition and health in African American men. J Aging Health. 2015;27(2):195-219.

90. LaVeist-Ramos TA, Galarraga J, Thorpe RJ, Jr., Bell CN, Austin CJ. Are black Hispanics black or Hispanic? Exploring disparities at the intersection of race and ethnicity. J Epidemiol Community Health. 2012;66(7):e21.

91. Ray M, Sano M, Wisnivesky JP, Wolf MS, Federman AD. Asthma control and cognitive function in a cohort of elderly adults. J Am Geriatr Soc. 2015;63(4):684-691.

92. Zamroziewicz M, Raskin SA, Tennen H, Austad CS, Wood RM, Fallahi CR, Dager AD, et al. Effects of drinking patterns on prospective memory performance in college students. Neuropsychology. 2017;31(2):191-199.

93. Fama R, Le Berre AP, Hardcastle C, Sassoon SA, Pfefferbaum A, Sullivan EV, Zahr NM. Neurological, nutritional and alcohol consumption factors underlie cognitive and motor deficits in chronic alcoholism. Addict Biol. 2019;24(2):290-302.

94. Indiana University-Purdue University Indianapolis School of Science. Despite lower levels of drinking, African-Americans encounter more problems, study finds. ScienceDaily. 2014.

95. Zinn S, Stein R, Swartzwelder HS. Executive functioning early in abstinence from alcohol. Alcohol Clin Exp Res. 2004;28(9):1338-1346.

96. Fein G, Torres J, Price LJ, Di Sclafani V. Cognitive performance in long-term abstinent alcoholic individuals. Alcohol Clin Exp Res. 2006;30(9):1538-1544.

97. Heinz AJ, Fogler KA, Newcomb ME, Trafton JA, Bonn-Miller MO. Problematic alcohol use among individuals with HIV: relations with everyday memory functioning and HIV symptom severity. AIDS Behav. 2014;18(7):1302-1314.

98. Sankar A, Wunderlich T, Neufeld S, Luborsky M. Seropositive African Americans' beliefs about alcohol and their impact on antiretroviral adherence. AIDS Behav. 2007;11:195-203.

99. Brew BJ, Gonzalez-Scarano F. HIV-associated dementia: an inconvenient truth. Neurology. 2007;68(5):324-325.

100. Spronk DB, van Wel JH, Ramaekers JG, Verkes RJ. Characterizing the cognitive effects of cocaine: a comprehen- sive review. Neurosci Biobehav Rev. 2013;37(8):18381859.

101. Meade CS, Conn NA, Skalski LM, Safren SA. Neurocognitive impairment and medication adherence in HIV patients with and without cocaine dependence. J Behav Med. 2011;34(2):128-138.

102. Elliott JC, Aharonovich E, O'Leary A, Wainberg M, Hasin DS. Drinking motives among HIV primary care patients. AIDS Behav. 2014;18(7):1315-1323.

103. Evans SD, Williams BE, Leu CS. Correlates of posttraumatic growth among African Americans living with HIV/AIDS in Mississippi. Online J Rural Urban Res. 2013;3(1).

104. Sanders LMJ, Hortobagyi T, la Bastide-van Gemert S, van der Zee EA, van Heuvelen MJG. Dose-response relationship between exercise and cognitive function in older adults with and without cognitive impairment: A systematic review and meta-analysis. PLoS One. 2019;14(1):e0210036.

105. Joseph RP, Ainsworth BE, Mathis L, Hooker SP, Keller C. Utility of Social Cognitive Theory in Intervention Design for Promoting Physical Activity among African-American Women: A Qualitative Study. Am J Health Behav. 2017;41(5):518-533.

106. Brewster PW, Melrose RJ, Marquine MJ, Johnson JK, Napoles A, MacKay-Brandt A, Farias S, et al. Life experience and demographic influences on cognitive function in older adults. Neuropsychology. 2014;28(6):846-858.

107. Henderson KA, Ainsworth BE. Sociocultural perspectives on physical activity in the lives of older African American and American Indian women: a cross cultural activity participation study. Women Health. 2000;31(1):1-20.

108. Dunn MZ. Psychosocial mediators of a walking intervention among African American women. J Transcult Nurs. 2008;19(1):40-46.

109. Harley AE, Odoms-Young A, Beard B, Katz ML, Heaney CA. African American social and cultural contexts and physical activity: strategies for navigating challenges to participation. Women Health. 2009;49(1):84-100.

110. Wilbur J, Chandler P, Dancy B, Choi J, Plonczynski D. Environmental, policy, and cultural factors related to physical activity in urban, African American women. Women Health. 2002;36(2):17-28. 